\title{
The Effect of Feeding Laying Hen Conventional and Omega-3 Enriched Diet on Fatty Acid Profiles in Egg Yolk Lipids
}

\author{
Gordana Kralik $^{1}$, Zlata Kralik ${ }^{1}$, Manuela Grčević ${ }^{1}$, Igor Kralik ${ }^{2}$ and Danica Hanžek ${ }^{1}$ \\ 1. Department of Special Zootechnics, Faculty of Agriculture in Osijek, Josip Juraj Strossmayer University of Osijek, Osijek 31000 , \\ Croatia \\ 2. Department of Agroeconomics, Faculty of Agriculture in Osijek, Josip Juraj Strossmayer University of Osijek, Osijek 31000 , \\ Croatia
}

\begin{abstract}
The aim of this research was to enrich table eggs with n-3 polyunsaturated fatty acids (n-3 PUFA), especially with essential eicosapentaenoic acid (EPA) and docosahexaenoic acid (DHA). After five weeks of feeding of laying hens with standard and experimental diets, there was analysis carried out to determine the fatty acid profile in egg yolks of both groups. Omega-3 eggs contain statistically significantly $(P<0.05)$ less sum of saturated fatty acids $(\Sigma$ SFA) and more $\Sigma \mathrm{n}-3$ PUFA, as well as narrower ratio of $\Sigma \mathrm{n}-6 / \Sigma \mathrm{n}-3$ PUFA than conventional eggs. If referring to individual fatty acids of omega-3 eggs, there were increased portions $(P<$ 0.05 ) of $\alpha$-linolenic acid ( $\alpha$-LNA), docosapentaenoic acid (DPA), EPA and DHA determined in this research, which was in line with the research objective. Within the presented research, concentration of n-3 PUFA in egg yolk lipids of experimental group was two times higher than that in the control group. The ratio of $\Sigma$ n-6 PUFA/ $5 n-3$ PUFA was reduced from 12.04 to 6.17. Within their enzymatic system, laying hens can act as a bioreactor to naturally enrich their eggs with n-3 PUFA, especially with EPA and DHA. The results of this research proved that the fatty acid profile can be modified by designing of laying hens' diets with specific forages. Eggs were enriched with favorable fatty acids in the following order: $\alpha$-LNA $>$ DHA $>$ DPA $>$ EPA.
\end{abstract}

Key words: Laying hen, egg yolk, PUFA, EPA, DHA.

\section{Introduction}

Table eggs are considered as a functional product or food $[1,2]$. Products designed to preserve human cardiovascular system should contain higher portions of n-3 polyunsaturated fatty acids (n-3 PUFA), the ratio of which shall be balanced with n-6 PUFA. Human organism needs n-3 PUFA as well as n-6 PUFA. Many health organizations recommend the n-6/n-3 PUFA ratio to range from $3: 1$ to $10: 1$, however, in reality, that ratio reaches $15: 1$ in USA, and 1:1 to 3:1 in Japan [3-5].

Research results obtained in the Republic of Croatia indicated that the ratio of $n-6 / n-3$ PUFA in eggs was ranging from 11:1 [6] up to 35:1 [7]. Feng and

Corresponding author: Gordana Kralik, professor, research fields: biotechnical sciences, animal products quality.
Scheideler [8] pointed out that PUFA were the main eight components of cellular fluid and membranes, and they were important in many biological functions by having a role of receptors, transmitters and by affecting enzymatic and immune systems. Two polyunsaturated fatty acids: linoleic (LA, C18:2n-6) from n-6 PUFA group and $\alpha$-linolenic acid ( $\alpha$-LNA, C18:3n-3) from n-3 PUFA group are essential fatty acids, because they can not be synthesized in an organism, but need to be taken in through food. In an animal organism, LA and $\alpha$-LNA can be deposited, and they can oxidize or metabolize into long chain acids in highly unsaturated fatty acids through elongation and desaturation. LA is converted to $\gamma$-linolenic acid (GLA, C18:3n-6), dihomo-gamma-linolenic acid (DGLA, C20:3n-6) and 
arachidonic acid (AA, C20:4n-6). LNA is metabolized into eicosapentaenoic (EPA, C20:5n-3) and docosahexaenoic acid (DHA, C22:6n-3). They can not be mutually converted, but they compete for the same enzymes $-\Delta 6$ and $\Delta 5$ desaturase during desaturation of their long chain homologs [9].

AA affects growth in early life. Leaf et al. [10] reported on positive correlation between body weight and concentration of $\mathrm{AA}$ in plasma triglycerides. Almost one-thirds of fatty acids in human cortex refer to DHA, which has an important role in brain and retina functions. Provision of PUFA is crucial for normal development. Deficiency of PUFA can cause damages to human cells and brain. Also, provision of essential fatty acids is important for retina development in puberty [11]. Deficiency of $n-3$ or $n-6$ PUFA causes unfavorable physical or biochemical changes, however, surplus of essential fatty acids also has unfavorable effects. Balance between n- 6 and n-3 PUFA depends on their content in food. Absolute amount of each acid is also important, because there is competitive inhibition between two series of fatty acids for $\Delta 5$ and $\Delta 6$ desaturases. EPA and DHA compete with AA in production of eicosanoids [12]. Food rich in n-6 fatty acid changes its viscosity, vasoconstriction and reduces bleeding time. On the other hand, large quantities of n-3 fatty acid increase the need for antioxidants and vitamin $\mathrm{E}$, reduce platelet aggregation, inhibit metabolism of AA during formation of prostaglandins and cause immunosuppression [12]. According to the Health and Welfare Canada [13], recommended ratio of $n-6 / n-3$ shall range from 4:1 to 10:1 for young people.

The aim of this research was to enrich table eggs with n-3 PUFA, especially with EPA and DHA by manipulating the feed.

\section{Materials and Methods}

The research was carried out on 250 laying hens of the Tetra SL line. Laying hens were kept in two groups. Each group had five replicates with 25 hens.
All were fed and watered ad libitum. Eggs were collected and analyzed after 21 days of feeding. Composition of diets used in production of conventional eggs (standard diet, K) and eggs enriched with n-3 PUFA (experimental diet, P) is overviewed in Table 1, and the food analysis methods are according to Refs. [14-19]. Profile of fatty acids in egg yolk lipids was determined according to the method of Csapo et al. [20] by using Chrompack CP-9000 chromatograph equipped with flame ionization detector. The analysis was performed on 10 eggs per group (two eggs per each replicate).

Research results were analyzed in STATISTICA version 8.0 [21]. Differences between tested groups were determined by using the $t$-test, and the statistically significant differences level between experimental groups were at $P<0.05$.

\section{Results and Discussion}

In Table 2, there is an overview of fatty acids profile of standard diet $(\mathrm{K})$ and experimental diet $(\mathrm{P})$, which contains high percentage of $\alpha$-LNA for 2.50 times, as well as $0.88 \%$ EPA and $1.59 \%$ DHA (in total fatty acids) in experimental diet, but it is not the case with standard diet. Experimental diet contained the mixture of oils: soybean $1.25 \%$, rapeseed $2 \%$, linseed $1 \%$ and fish $0.75 \%$, so that the diet contained $0.88 \%$ EPA, $0.16 \%$ DPA, $1.5 \%$ DHA and $8.33 \% \alpha$-LNA. Diet fed to the control group contained only $3.33 \%$ $\alpha$-LNA. In this way, modified diet affected double deposition of $\Sigma$ n-3 PUFA, especially EPA and DHA in egg yolks of experimental group when compared with the control. Surai and Sparks [1], Fraeye et al. [2], Kralik et al. [6] and Sim [22] reported on the effects of modified feed on the composition of fatty acids in yolks. Due to decreased portion of 5 n- 6 PUFA in experimental diet from $48.83 \%$ to $38.45 \%$, and increased portion of $\Sigma$ n-3 PUFA from $3.33 \%$ to $10.96 \%$ in total fatty acids, the ratio of $\Sigma n-6 / \Sigma n-3$ PUFA was also decreased from 14.66 to 3.51. After five weeks of feeding laying hens with standard and experimental 
Table 1 Composition and chemical analysis of laying hens' diets.

\begin{tabular}{|c|c|c|}
\hline Ingredient $(\%)$ & Standard diet $(\mathrm{K})$ & Experimental diet $(\mathrm{P})$ \\
\hline Corn & 40.81 & 47.08 \\
\hline Soybean cake & 18.50 & 21.66 \\
\hline Soybean toasted & 8.30 & 4.04 \\
\hline Triticale & 15.00 & - \\
\hline Sunflower cake & 1.65 & 6.00 \\
\hline Alfalfa & 1.00 & 2.50 \\
\hline Livestock yeast & 0.50 & 1.00 \\
\hline Limestone & 9.36 & 10.24 \\
\hline Monocalcium phosphate & 1.56 & 1.50 \\
\hline Livestock salt & 0.32 & 0.32 \\
\hline Synthetic methionine & 0.24 & 0.16 \\
\hline Sunflower oil & 2.26 & - \\
\hline Oil mixture & - & 5.00 \\
\hline Premix $^{1,2}$ & 0.50 & 0.50 \\
\hline Total & 100.00 & 100.00 \\
\hline \multicolumn{3}{|l|}{ Chemical analysis of $\operatorname{diets}^{3}(\mathrm{~g} / \mathrm{kg})$} \\
\hline Moisture & 87 & 81 \\
\hline Crude protein & 190 & 202 \\
\hline Crude fibers & 40 & 52 \\
\hline Ash & 139 & 169 \\
\hline Fat & 52 & 65 \\
\hline $\mathrm{Ca}$ & 41 & 51 \\
\hline Metabolizable energy (kcal/kg) & 2,789 & 2,772 \\
\hline
\end{tabular}

Premix mixture $\mathrm{K}$ contains in $1 \mathrm{~kg}$ : vitamin A 200,000 UI, vitamin $\mathrm{D}_{3}$ 500,000 UI, vitamin E 10,000 mg, vitamin $\mathrm{K}_{3} 600 \mathrm{mg}$, vitamin $B_{1} 400 \mathrm{mg}$, vitamin $B_{2} 1,000 \mathrm{mg}$, vitamin $B_{6} 1,000 \mathrm{mg}$, vitamin $B_{12} 3,000 \mu \mathrm{g}$, vitamin $C$ 4,000 mg, vitamin $\mathrm{H} 12 \mathrm{mg}$, vitamin $B_{3} 8,000 \mathrm{mg}$, vitamin $B_{5} 2,400 \mathrm{mg}$, vitamin $B_{9} 150 \mathrm{mg}$, vitamin $B_{4} 100,000 \mathrm{mg}$, iodine $200 \mathrm{mg}$, manganese 18,000 mg, zinc $14,000 \mathrm{mg}$, cobalt $30 \mathrm{mg}$, iron 12,000 mg, copper 1,600 mg, selenium inorganic $50 \mathrm{mg}$, calcium $238 \mathrm{~g}$, phytase 100,000 FYT, canthaxanthin $500 \mathrm{mg}$, beta-apo-beta carotene-acid $300 \mathrm{mg}$, antioxidant (butylated hydroxytoluene) 20,000 mg.

${ }^{2}$ Premix mixture $\mathrm{P}$ contains in $1 \mathrm{~kg}$ : vitamin A 200,000 UI, vitamin $\mathrm{D}_{3} 500,000 \mathrm{UI}$, vitamin E 20,000 mg, vitamin $\mathrm{K}_{3} 400 \mathrm{mg}$, vitamin $B_{1} 420 \mathrm{mg}$, vitamin $B_{2} 900 \mathrm{mg}$, vitamin $B_{6} 540 \mathrm{mg}$, vitamin $B_{12} 2,300 \mathrm{mg}$, vitamin $B_{9} 170 \mathrm{mg}$, pantothenic acid 1,400 mg, vitamin $B_{3} 5,000 \mathrm{mg}$, vitamin $H 17,000 \mu \mathrm{g}$, vitamin $B_{4} 80,000 \mathrm{mg}$, vitamin $C 4,500 \mathrm{mg}$, iodine $180 \mathrm{mg}$, manganese $14,000 \mathrm{mg}$, zinc $12,500 \mathrm{mg}$, iron $6,000 \mathrm{mg}$, copper $1,000 \mathrm{mg}$, selenium inorganic $80 \mathrm{mg}$, butylated hydroxytoluene $3,400 \mathrm{mg}$, propylgallate $1,400 \mathrm{mg}$, canthaxanthin $600 \mathrm{mg}$, beta-apo-8'-carotene-acid-ethylester $200 \mathrm{mg}$.

${ }^{3}$ Referential methods used for chemical analysis of diets: HRN ISO 6496 [14], HRN EN ISO 5983-2 [15] and HRN EN ISO 6865 [16], modified according to instructions of FOSS Fiber Cap manual; HRN ISO 5984 [17] and HRN ISO 6492 [18], modified according to instructions of extraction system ANKOM XT15; RU-5.4.2-11 (internal method); HRN EN ISO 6869 [19].

Table 2 Profile of fatty acids in laying hens' diet (\% of total fatty acids).

\begin{tabular}{lll}
\hline Fatty acid & Standard diet $(\mathrm{K})$ & Experimental diet $(\mathrm{P})$ \\
\hline$\Sigma$ SFA $^{1}$ & 21.05 & 16.38 \\
$\Sigma$ MUFA $^{2}$ & 26.96 & 34.20 \\
$\Sigma \mathrm{n}-6$ PUFA $^{3}$ & 48.83 & 38.45 \\
$\alpha$-LNA C18:3n-3 & 3.33 & 8.33 \\
ETA C20:3n-3 & - & - \\
EPA C20:5n-3 & - & 0.88 \\
DPA C22:5n-3 & - & 0.16 \\
DHA C22:6n-3 & - & 1.59 \\
$\Sigma$ n-3 PUFA & 3.33 & 10.96 \\
\hline
\end{tabular}

इSFA: C12:0 + C14:0 + C15:0 + C16:0 + C17:0 + C18:0 + C20:0 + C22:0 + C23:0 + C24:0.

${ }^{2} \Sigma$ MUFA: C16:1 + C18:1n-9t + C18:1n-9c + C18:1 + C20:1n-9+C22:1n-9.

${ }^{3}$ SPUFA: C18:2n-6 + C18:3n-6 + C20:2 + C20:4n-6 + C18:2A + C18:2B + C18:2C + C18:2D. 
The Effect of Feeding Laying Hen Conventional and Omega-3

Enriched Diet on Fatty Acid Profiles in Egg Yolk Lipids

Table 3 Profile of fatty acids in yolk lipids of conventional and omega-3 eggs (\% of total fatty acids).

\begin{tabular}{lll}
\hline Fatty acid & Conventional eggs & Omega-3 eggs \\
\hline$\Sigma$ SFA $^{1}$ & $35.34 \pm 1.77^{\mathrm{a}}$ & $32.95 \pm 1.05^{\mathrm{b}}$ \\
$\Sigma$ MUFA $^{2}$ & $41.21 \pm 2.03$ & $42.45 \pm 0.87$ \\
$\Sigma$ n-6 PUFA & $21.74 \pm 1.44$ & $21.17 \pm 1.33$ \\
$\alpha$-LNA C18:3n-3 & $0.89 \pm 0.18^{\mathrm{b}}$ & $2.03 \pm 0.31^{\mathrm{a}}$ \\
ETA C20:3n-3 & $0.01 \pm 0.005^{\mathrm{b}}$ & $0.02 \pm 0.004^{\mathrm{a}}$ \\
EPA C20:5n-3 & $0.01 \pm 0.004^{\mathrm{b}}$ & $0.06 \pm 0.01^{\mathrm{a}}$ \\
DPA C22:5n-3 & $0.09 \pm 0.03$ & $0.10 \pm 0.02$ \\
DHA C22:6n-3 & $0.68 \pm 0.22^{\mathrm{b}}$ & $1.22 \pm 0.06^{\mathrm{a}}$ \\
$\Sigma \mathrm{n}-3$ PUFA & $1.68 \pm 0.39^{\mathrm{b}}$ & $3.43 \pm 0.28^{\mathrm{a}}$
\end{tabular}

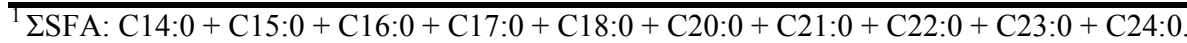

${ }^{2}$ LMUFA: C14:1 + C16:1 + C18:1n-9t + C18:1n-9c + C18:1 + C20:1n-9.

${ }^{3}$ EPUFA: C18:2n-6 + C18:2A + C18:2B + C18:2C + C18:2D + C18:3n-6 + c9,t11-CLA + C20:2 + C20:3n-6 + C20:4n-6 + C22:4n-6.

${ }^{\mathrm{a}, \mathrm{b}}$ Mean numbers in rows with different letters differ statistically at $P<0.05$.

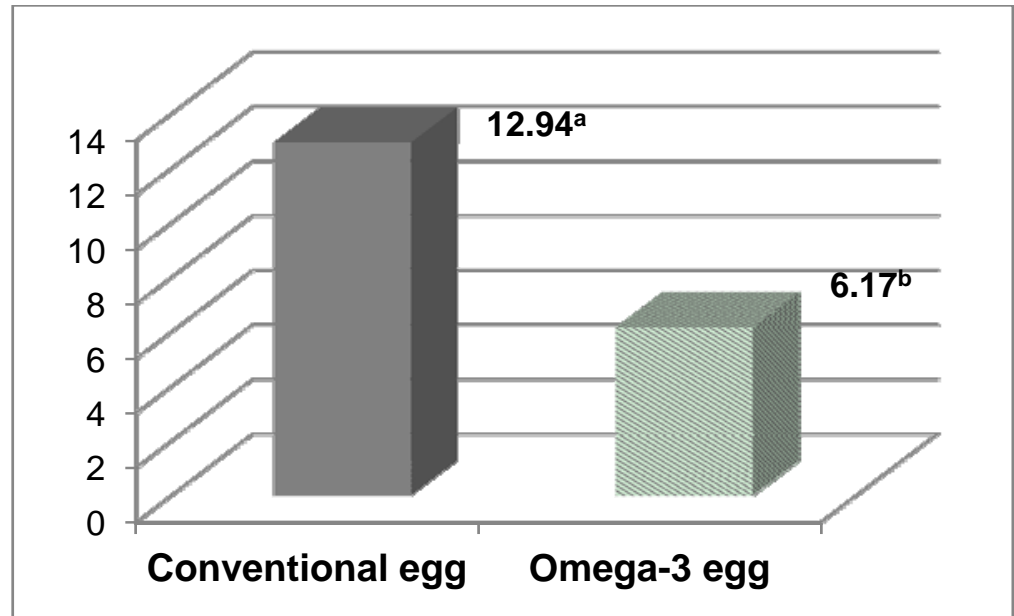

Fig. 1 The $\Sigma n-6 / \Sigma n-3$ PUFA ratio in yolk lipids.

${ }^{\mathrm{a}, \mathrm{b}}$ Mean numbers marked with different letter differ statistically at $P<0.05$.

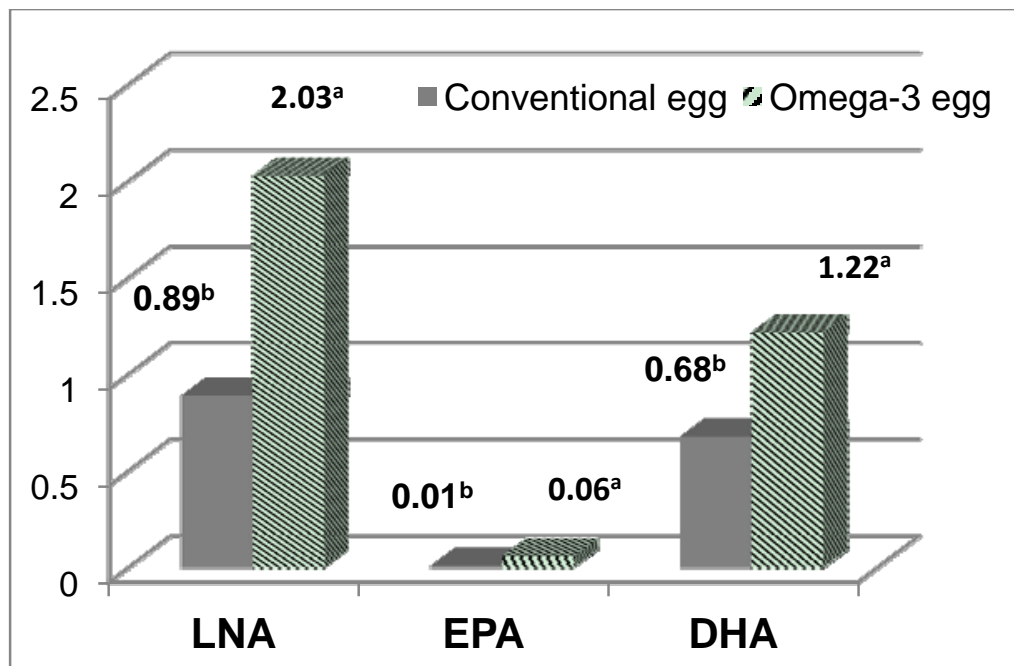

Fig. 2 Portion of $\alpha$-LNA, EPA and DHA.

a, b Mean numbers marked with different letter differ statistically at $P<0.05$. 
diets, produced eggs were collected with the aim to analyze the fatty acid profile in egg yolks of both laying hens groups.

Table 3 presents profile of fatty acids in yolk lipids of conventional and omega-3 eggs. Omega-3 eggs contain statistically significantly $(P<0.05)$ less saturated fatty acids ( $\Sigma$ SFA) and more $\Sigma$ n-3 PUFA, as well as lower ratio of $\Sigma n-6 / \Sigma n-3$ PUFA than conventional eggs. If referring to individual fatty acids in omega-3 eggs, there were increased portions $(P<$ $0.05)$ of $\alpha$-LNA, EPA, DPA and DHA, which was the aim of this research. Surai and Sparks [1] claimed that eggs could be enriched with n-3 PUFA in two ways. One simpler way is to enrich eggs with $\alpha$-LNA, which is a precursor of EPA and DHA, by feeding of laying hens diets with linseed oil. The other way of enriching eggs with n-3 PUFA is supplementation of fish oil to diets, because it contains desirable DHA that is along with newly synthetized EPA and DHA, deposited in egg yolks. This was the case in this research.

Fig. 1 shows the ratio of $\Sigma n-6 / \Sigma n-3$ PUFA in yolk lipids of analyzed eggs. Results of this research, as well as of other authors, proved that the profile of fatty acids can be modified through composition of laying hens' diets with specific forages. Hargis et al. [23] investigated the omega-3 FA in egg yolk with respect to dietary supplementation with $3 \%$ of fish oil in comparison with fat supplementation. When referring to fish oil, eggs contained $235 \mathrm{mg}$ of n-3 FA, of which EPA and DHA took up $89 \%$. In order to avoid unfavorable fishy odor, Scheideler and Froning [24] used linseed or linseed oil rich in $\alpha$-LNA, because it got incorporated into egg yolk in form of n-3 PUFA. They determined that $\alpha$-LNA was represented in the highest portion, but there were also long-chain n-3 PUFA, such as EPA, DPA and DHA, found in phospholipid fraction. This fact pointed out that hens fed with linseed could convert $\alpha$-LNA to EPA, DPA and DHA by means of enzymes of desaturase and elongase. Hens fed with linseed produced eggs enriched with fatty acids in the following order: $\alpha$-LNA $>$ DHA $>$ DPA $>$ EPA [19]. Scheideler and Froning [24] reported that $\alpha$-LNA was increased linearly to supplementation of 5\%,10\% and $15 \%$ of linseed, which was not the case with DHA.

Hens as bioreactors can activate the enzymatic system to naturally enrich eggs with n-3 PUFA, especially with EPA and DHA (Fig. 2).

\section{Conclusions}

Results of the presented research proved that modification of diet composition for laying hens can successfully alter the profile of fatty acids in yolk lipids of table eggs. Laying hens can incorporate fatty acids from feed directly in yolks and convert short-chain fatty acids into those of long carbon chain. Eggs enriched with functional ingredients, such as n-3 PUFA, represent a product of better nutritional quality. In this research, concentration of n-3 PUFA in egg yolk lipids of experimental group was two times higher than that in the control group. The ratio of $\Sigma$ n- 6 PUFA/ $\Sigma$ n-3 PUFA was reduced from 12.04 to 6.17 .

\section{Acknowledgments}

The research was carried out within the project "Pig and Poultry Growth Characteristics and Quality of Products" (No. 079-0790566-0567), funded by the Ministry of Science, Education and Sports of the Republic of Croatia.

\section{References}

[1] Surai, P. F., and Sparks, N. H. C. 2001. "Designer Eggs: From Improvement of Egg Composition to Functional Food.” Trends in Food Sci. Technol. 12 (1): 7-16.

[2] Fraeye, I., Bruneel, C., Lemahieu, C., Buyse, J., Muylaert, K., and Foubert, I. 2012. "Dietary Enrichment of Eggs with Omega-3 Fatty Acids: A Review." Food Res. Int. 48 (2): 961-9.

[3] Grashorn, M. A. 2007. "Functionality of Poultry Meat." J. Appl. Poult. Res. 16 (1): 99-106.

[4] Molendi-Coste, O., Legry, V., and Leclercq, I. A. 2011. "Why and How Meet n-3 PUFA Dietary Recommendations?" Gastroenterology Research and Practice Vol. 2011. doi:10.1155/2011/364040. 


\section{The Effect of Feeding Laying Hen Conventional and Omega-3 Enriched Diet on Fatty Acid Profiles in Egg Yolk Lipids}

[5] Patterson, E., Wall, R., Fitzgerald, G. F., Ross, R. P., and Stanton, C. 2012. "Health Implications of High Dietary Omega-6 Polyunsaturated Fatty Acids." Journal of Nutrition and Metabolism Vol. 2012. doi:10.1155/2012/539426.

[6] Kralik, G., Gajčević, Z., and Škrtić, Z. 2008. "The Effect of Different Oil Supplementations on Laying Performance and Fatty Acid Composition of Egg Yolk." Ital. J. Anim. Sci. 7 (2): 173-83.

[7] Škrtić, Z., Kralik, G., Gajčević, Z., Bogut, I., and Hanžek, D. 2007. "The Increase of the n-3 PUFA Content in Eggs." Poljoprivreda (Agriculture) 13 (2): 47-52.

[8] Feng, Z., and Scheideler, S. E. 1998. n-3 and n-6 Fatty Acids and Modified Egg in the Human Diet. UNL Poultry Report, University of Nebraska.

[9] Calvani, M., and Benatti, P. 2003. "Polyunsaturated Fatty Acids." Sigma-Tau S.p.A.-Scientific Department, Pomezia, Italy. Accessed March 24, 2015. http://www.ibrarian.net/navon/paper/Polyunsaturated_Fat ty_Acids.pdf?paperid=2446592.

[10] Leaf, A. A., Leighfield, M. J., Costeloe, K. L., and Crawford, M. A. 1992. "Factors Affecting Long-Chain Polyunsaturated Fatty Acid Composition of Plasma Choline Phosphoglycerides in Preterm Infants." J. Pediatr. Gastr. Nutr. 14 (3): 300-8.

[11] Carlson, S. E., Werkman, S. H., Rhodes, P. G., and Tolley, E. A. 1993. "Visual Acuity Development in Healthy Preterm Infants: Effect of Marine Oil Supplementation.” Am. J. Clin. Nutr. 58 (1): 35-42.

[12] Simopoulos, A. P. 1991. "Omega-3 Fatty Acids in Health and Disease and in Growth and Development." Am. J. Clin. Nutr. 54 (3): 438-63.

[13] Health and Welfare Canada. 1990. Nutrition
Recommendations. Ottawa, Canada: Minister of Supply and Services.

[14] Croatian Standards. 2001. Determination of Water: HRN ISO 6496.

[15] Croatian Standards. 2010. Determination of Nitrogen Content and Calculation of Crude Protein Amount: HRN EN ISO 5983-2.

[16] Croatian Standards. 2001. Determination of Crude Fiber Content: HRN EN ISO 6865.

[17] Croatian Standards. 2004. Determination of Ash: HRN EN ISO 5984.

[18] Croatian Standards. 2001. Determination of Fat Content: HRN ISO 6492.

[19] Croatian Standards. 2001. Determination of Ca Content: HRN EN ISO 6869.

[20] Csapó, J., Sugár, L., Horn, A., and Csapo-Kiss, Z. 1986. "Chemical Composition of Milk from Red Deer, Roe and Fallow Deer Kept in Captivity." Acta Agronomica Hungarica 36 (3-4): 359-72.

[21] StatSoft, Inc.. 2012. STATISTICA Version 8.0. Data Analysis Software System.

[22] Sim, J. S. 1993. "Designing Eggs and Health/Nutritional Implication for Egg Consumers." In Proceedings of the 54th Minnesota Nutrition Conference and National Renders Technical Symposium, 275-86.

[23] Hargis, P. S., Van Elswyk, M. E., and Hargis, B.M. 1991. "Dietary Modification of Yolk Lipid with Menhaden Oil." Poultry Sci. 70 (4): 874-83.

[24] Scheideler, S. E., and Froning, G. W. 1996. "The Combined Influence of Dietary Flaxseed Variety, Level, Form and Storage Conditions on Egg Production and Composition among Vitamin E-Supplemented Hens." Poultry Sci. 75 (10): 1221-6. 